\title{
Titanium Dioxide Rectifiers
}

\author{
R. G. Breckenridge and W. R. Hosler
}

\begin{abstract}
A new type of metal rectifier is described which utilizes a film of semiconducting titanium dioxide produced on titanium metal. These rectifiers, which have been prepared either by a two-step process involving a heating of the metal in oxygen followed by a reduction of the oxide in hydrogen or by a single heating of the metal in water vapor, are shown to have properties comparing favorably with existing types, particularly for high temperature applications. The properties of the units in regard to the nature of the counter electrode, and relation to theories of rectification are discussed.
\end{abstract}

\section{Introduction*}

The phenomenon of rectification at a metal-semiconductor contact has been of commercial as well as scientific importance since the first announcement of the cuprous oxide rectifier by Grondahl in 1926 $[1] . \dagger$ Since this first practical rectifier was produced, a number of other somewhat similar types have appeared, the magnesium copper sulfide [2] and the selenium [2] rectifiers being widely used commercially. While the point contact types, such as the silicon and germanium rectifiers [3], are similar in principle, they are designed for handling small amounts of radiofrequency power instead of rather large amounts of low-frequency power.

There have been a great number of theories proposed to explain rectification, the most widely used probably being those of Mott [4] and Schottky [5]. Although these theories differ considerably in their details, both discuss a model consisting of an asymmetrical potential barrier such that charge carriers are transferred readily across the barrier in one direction and with difficulty in the other. It is in the nature of this barrier, e. g., chemical, physical, or both, and in the mathematical details describing the charge flow in the various possible situations that the differences arise. Unfortunately, the multiplicity of theories has not materially aided the search for new or improved rectifiers, and their discovery still seems almost fortuitous. The properties of the $\mathrm{Cu}-\mathrm{Cu}_{2} \mathrm{O}$ system are, however, at least suggestive of the properties needed for a practical rectifier of the oxide type. It is evident that the oxide must be readily produced as a thin, tightly adhering layer on the metal surface, the oxide composition must be controllable so that it may be made a semiconductor with a relatively high conductivity, and finally, there must be some means of producing an asymmetrical potential barrier in the system. In the $\mathrm{Cu}_{2} \mathrm{O}$ rectifier there is some evidence [6] that the barrier is a layer of nearly stoichiometric $\mathrm{Cu}_{2} \mathrm{O}$ at the $\mathrm{Cu}_{2} \mathrm{O}-\mathrm{Cu}$ interface.

Even a brief consideration of the first two rather obvious requirements serves to eliminate the great majority of the metal-oxide combinations, since there are very few oxides that are readily produced with conductivities great enough to be of interest (about

*The results of this work were first presented at the National Research Council's Conference on Electrical Insulation meeting in Washington, D. C., Oct. $29-31,1951$.

$\dagger$ Figures in brackets indicate the literature references at the end of this paper.
1 to $10 \Omega^{-1} \mathrm{~cm}^{-1}$ at room temperature), let alone in the form of a thin adherent film.

Some observations on the oxidation of titanium metal [7] have shown, however, that a thin film satisfying the mechanical requirements is readily produced on the metal surface. Similarly, there have been a number of studies of the electrical properties of titanium dioxide semiconductors [8 to 12] showing that the oxide can be made an $n$-type semiconductor with a conductivity in the desired range by heating the oxide in hydrogen. It is then apparent that at least the possibility exists for a feasible rectifier unit, providing that in some way the asymmetrical potential barrier may be produced. The formation of this barrier seems not unlikely, since a concentration gradient similar to that in the $\mathrm{Cu}_{2} \mathrm{O}$ rectifier might be formed at the metal-oxide interface or possibly at the oxide surface. A number of experiments on this system have been carried out, and two methods of producing such a rectifier have been developed. Although the unit is still in an early stage of development, the observed characteristics are comparable to those reported for commercially available types. It should be mentioned that, in common with other rectifier developments, it has proved difficult to obtain entirely consistent results, so the numerical values quoted later in the paper should be regarded as representative and not necessarily final values.

\section{Titanium Oxide Films}

The titanium metal used in these studies was obtained through the courtesy of the AlleghenyLudlum Steel Co., Watervliet, N. Y. The sample was in the form of a sheet $0.015 \mathrm{in}$. thick of standard commercial grade Ti $75 \mathrm{~A}$, reported by the company to be about 99.5 percent pure, with 0.1 percent of $\mathrm{Fe}, 0.02$ percent of $\mathrm{N}$, a trace of $\mathrm{O}, \mathrm{C}<0.04$ percent, and variable amounts of $\mathrm{W}$ present as inclusions ranging from 0.05 to 0.5 percent. This metal was cut into $1 / 2$-in. squares and ground with No. 400 alundum. A few trials were also made with the unpolished sheet, and no pronounced differences in the electrical results were noted. In the first series of studies, these squares, contained in a small porcelain boat, were placed in the furnace without protection. More consistent results were obtained if they were imbedded in $\mathrm{Al}_{2} \mathrm{O}_{3}$ powder, and this procedure was followed in most of the studies. The samples were 
TABle 1. Properties of titanium oxide films

\begin{tabular}{|c|c|c|c|c|c|c|}
\hline \multirow{2}{*}{$\begin{array}{l}\text { Tem- } \\
\text { pera- } \\
\text { ture }\end{array}$} & \multicolumn{6}{|c|}{ Time } \\
\hline & $25 \mathrm{~min}$ & $1 \mathrm{hr}$ & $11 / 2 \mathrm{hr}$ & $2 \mathrm{hr}$ & $21 / 2 \mathrm{hr}$ & $9 \mathrm{hr}$ \\
\hline${ }^{\circ} \mathrm{C}$ & $\begin{array}{l}\text { Smooth, thin, light-grey, } \\
\text { tightly adhering coat.* } \\
\text { Breakdown voltage: } \\
\text { V+, } 60 \text { to } 90 ; \mathrm{V}-, 150 .\end{array}$ & & $\begin{array}{l}\text { Smooth, blue-grey, tight- } \\
\text { ly adhering coat.* } \\
\text { Breakdown voltage: } \\
\text { V+, } 120 \text { to } 150 \text {; V-- } \\
150 .\end{array}$ & $\begin{array}{l}\text { Smooth, tightly adher- } \\
\text { ing, grey-yellow coat. } \\
\text { Breakdown voltage: } \\
\text { V+, } 125, \mathrm{~V}-, 185 .\end{array}$ & $\begin{array}{l}\text { Grey-yellow, badly } \\
\text { chipped coat. } \\
\text { Breakdown volt- } \\
\text { age: V+, } 120 \text { to } \\
150 ; \text { V-, } 140 \text { to } \\
150 \text { Thickness } \\
0.0003 \text { in. }\end{array}$ & $\begin{array}{l}\text { B lu e - g r e y } \\
\text { thick, tightly } \\
\text { adhering coat. }\end{array}$ \\
\hline 820 & $\begin{array}{l}\text { Smooth, even, blue-grey, } \\
\text { tightly adhering coat.* } \\
\text { Breakdown voltage: } \\
\text { V+, } 60 ; \mathrm{V}-, 70 \text { to } 90 .\end{array}$ & $\begin{array}{l}\text { Smooth, even, blue-grey, } \\
\text { partially chipped coat.* } \\
\text { Breakdown voltage: } \\
\text { V+, } 60 \text { to } 90 \text {; V-, } 120 \\
\text { to } 150 \text { Thickness }\end{array}$ & $\begin{array}{l}\text { Grey-y ellow, partially } \\
\text { loose from surface coat.* } \\
\text { Breakdown voltage: } \\
\text { V+, } 120 ; \quad \text { V }, 150 . \\
\text { Thickness } 0.0001 \text { in. }\end{array}$ & $\begin{array}{l}\text { Grey, almost completely } \\
\text { chipped off coat.* } \\
\text { Breakdown voltage: } \\
\text { V+, } 120 \text { to } 150 ; \text { V - } \\
150 \text {.' Thickness } \sim 0.0001\end{array}$ & & \\
\hline 850 & $\begin{array}{l}\text { Yellow-grey, tightly } \\
\text { bound coat. Break- } \\
\text { down voltage: V+, } \\
>320 ; \mathrm{V}-,>320 \text {. } \\
\text { Yellow, loosely bound } \\
\text { coat. Breakdown volt- } \\
\text { age: V+, >320; V-, } \\
>320 \text {. }\end{array}$ & $\begin{array}{l}\text { Greenish-yellow rough } \\
\text { but tightly bound coat. } \\
\text { Breakdown voltage: } \\
\text { V+, >320; V-, > } 320 \text {. } \\
\text { Yellow, badly chipped coat. } \\
\text { Breakdown voltage: } \\
\text { V+, 450; V-, > } 500 \text {. } \\
\text { Thickness } 0.0008 \text { in. }\end{array}$ & $\begin{array}{l}\text { Yellow, tightly bound } \\
\text { coat. Breakdown volt- } \\
\text { age: V+, >320; V-, } \\
\text { 320. } \\
\text { White-yellow coat, } \\
\text { chipped at edges. } \\
\text { Breakdown voltage: } \\
\text { V+, >500; V- > >500. } \\
\text { Thickness } 0.002 \text { in. }\end{array}$ & $\begin{array}{l}\text { Yellow, partially chipped } \\
\text { coat. Breakdown volt- } \\
\text { age: V+, >320; V-, } \\
>320 \text {. }\end{array}$ & & \\
\hline
\end{tabular}

then heated to the desired temperature in a tube furnace regulated to $\pm 5{ }^{\circ} \mathrm{C}$, while a stream of inert gas, in this case helium, was flowing through the tube. When the system was stabilized, the helium was swept out by oxygen dried by a liquid air trap and the samples kept in 1 atmosphere of oxygen for the desired time. At the end of this time, the oxygen was swept out with helium and the furnace allowed to cool to room temperature.

The physical and electrical properties of these samples were then examined in a number of ways. Because the oxide film must be thick enough to withstand appreciable voltages before breakdown, the breakdown strength was first explored. The oxide was ground off on one corner of the square so that electrical contact could be made to the titanium metal. Then a small metal point of copper, about $0.1 \mathrm{~mm}$ in diameter, was placed on the surface and the voltage raised to breakdown. This was done for both directions of current flow on about 10 spots on the surface.

The thickness of some of these films was determined with a simple optical system. The oxide was chipped off the metal at one point. Then, using a small tripod on which a mirror was mounted, the displacement of a light beam was measured when one of the tripod points rested on metal or oxide. The sensitivity of the setup was $3.5 \mu / \mathrm{mm}$ of deflection on the scale.

The studies of the oxide films are reported in table 1 , where the physical appearance, measured thickness and typical breakdown voltages are given for the various samples. The polarity of the point contact is indicated for V. The samples oxidized without the $\mathrm{Al}_{2} \mathrm{O}_{3}$ covering are indicated with an asterisk. In some of the higher temperature samples, the oxide film was so loosely adherent or flaky that no further studies were made. It is apparent, however, that samples produced at about $800^{\circ} \mathrm{C}$ for a variety of times, ranging from $\frac{1}{2}$ to 9 hours, have very satisfactory electrical properties. An undesirable feature noted in the higher temperature samples was an embrittlement of the metal produced by a solution of the oxygen in the metal, as has been previously reported [13]. This embrittlement, while present, was not excessive in the $800^{\circ}$ samples.

The kinetics of the oxidation of Ti metal has been studied by several authors $[14,15,16]$ with conflicting results. It has not been clearly established whether the growth follows a parabolic, logarithmic, or linear law with time, and all authors find considerable deviations for times as short as those used in this investigation. The work reported here cannot resolve this difficulty because a wide scatter of the data was found. This seatter arises from the fact that precise measurements of thickness were not attempted, the difficulty of controlling the shorttime treatments, and the possibility of oxygen dissolving in the metal rather than forming a surface oxide.

\section{Reduced $\mathrm{TiO}_{2}$ Rectifiers}

The reduction of titanium dioxide by hydrogen has been studied in detail by Nasu [17], who concludes that the reaction product is $\mathrm{Ti}_{2} \mathrm{O}_{3}$. For the purposes of rendering the rutile semiconducting with a conductivity in the desired range, only a partial reduction is needed, corresponding to a formula of about $\mathrm{TiO}_{1.95}[11]$, that is, with a 2.5-percent excess of titanium, which is presumably present as the trivalent ion. This amount of reduction was achieved in solid ceramic samples of rutile by treatment with hydrogen for 10 minutes at $1,350^{\circ} \mathrm{C}$ [11]. As it was anticipated that the speed of reduction would be much greater in the thin films, a series of trial runs was made, following a procedure similar to that for the oxidation process, at temperatures of $450^{\circ}$ to $800^{\circ} \mathrm{C}$ and for times ranging from 5 to 60 minutes, using oxide films formed at $800^{\circ} \mathrm{C}$ for 9 hours. The samples were not imbedded in $\mathrm{Al}_{2} \mathrm{O}_{3}$ for the reduction in hydrogen. The most satisfactory properties resulted from a treatment at $500^{\circ} \mathrm{C}$ for 15 minutes, although this was not critical. For long reductions at temperatures much above $500^{\circ} \mathrm{C}$, however, the oxide film was found to flake off, and for lower temperatures the process was very slow. 
After reduction, the units were tested for rectification, using a small spot of metallic indium for the counter electrode. This electrode material was chosen because other studies have shown $[11,12]$ that no anomalous electrical effects arise at the interface of this metal and titania semiconductors. This preliminary testing was done with a simple circuit to display the current-voltage curve on a cathode-ray oscilloscope [2]. If a reasonable evidence of rectification was found, a counter electrode was applied for more detailed measurements. This counter electrode was conveniently applied by plating with a-c for about 30 seconds so that the sensitive areas would be preferentially coated. Electrodes of a variety of metals have been used with effects to be discussed in detail later in this paper. However, silver was used for the major portion of the work because it is readily plated and the metal does not oxidize easily under heat treatment. The properties of the rectifiers formed in this fashion were then studied, using conventional voltmeter-ammeter measurements, both with point contacts to individual sensitive spots and with an $0.08-\mathrm{cm}^{2}$ copper plate pressed to the electroplated surface to make a large area contact.

In the rectifier tests some nonlinearity was observed in almost all cases, but in a number of samples good rectifying properties were found. The sense of the rectification is such that the direction of easy flow of electrons is from the $n$-type semiconductor to the counter electrode; that is, the counter electrode is positive. A typical measurement of such a pointcontact rectifier formed by heating for 9 hours in $\mathrm{O}_{2}$ at $800^{\circ} \mathrm{C}$ followed by 15 minutes in $\mathrm{H}_{2}$ at $500^{\circ} \mathrm{C}$ is shown in figure 1 , where the current in milliamperes is plotted as a function of voltage. A more revealing method of plotting these data is shown in figure 2 , where the log of the current in milliamperes is plotted as a function of the voltage. The forward current as a function of voltage is described by an equation of the form

$$
I_{f}=A_{f}\left[e^{\alpha_{f}\left(V-I_{f} r\right)}-1\right]
$$

so that $\alpha_{f}, A_{f}$, and $r$, the spreading resistance, may be determined from the data of figure 2. For this sample the values found are $A_{f}=0.001 \mathrm{ma}, \alpha_{f}=9.4$ volts ${ }^{-1}$, and $r=21 \Omega$. This value of $r$ indicates a conductivity at room temperature of about $7.4 \Omega^{-1} \mathrm{~cm}^{-1}$ and thus is in the desired range. As is typical for such measurements [2] the value of $\alpha_{f}$ is considerably smaller than the theoretical value of 40 volts $^{-1}$ but is similar to those found for commercial units.

The reverse current for applied voltages greater than 0.5 may be described by an equation of the form

$$
I_{b}=A_{b}\left(e^{\alpha_{b} V}-1\right)
$$

with values of $A_{b}=0.38$ ma and $\alpha_{b}=0.35$ volt $^{-1}$. These results are also similar to those found for other rectifier types. A similar study of a plated sample, using an $0.08-\mathrm{cm}^{2}$ contact area, is shown in figures 3 and 4. The forward and reverse currents are described by the same equations with constants $\alpha_{f}=8.6$ volts $^{-1}, A_{f}=0.0033 \mathrm{ma}$, and $r=12 \Omega$ in the forward direction, and $\alpha_{b}=0.39$ volt $^{-1}$ and $A_{b}=$ $0.29 \mathrm{ma}$ for the reverse current.

While no highly specific conditional requirements were found for either the oxidation or reduction treatments, the general trend of the observations suggests an oxygen treatment of about 2 hours at

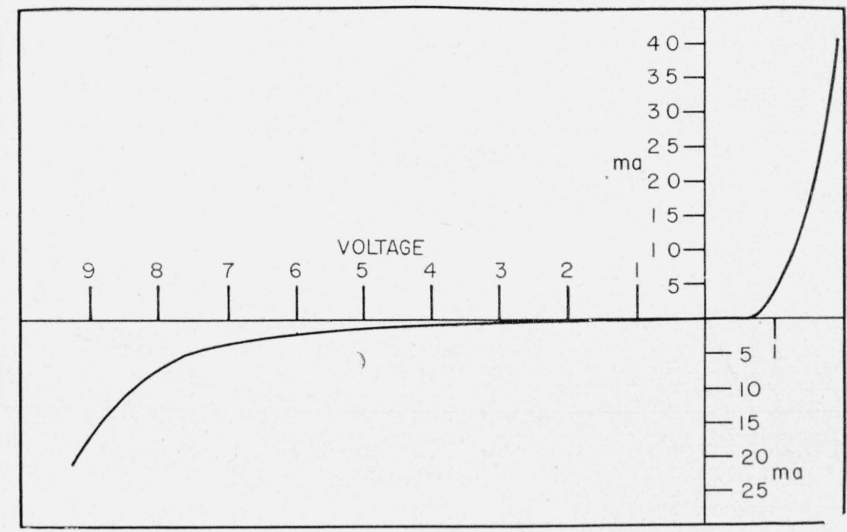

FIGURE 1. Direct-current rectifier characteristics from silver point contact on titanium dioxide rectifier made by two-step process.

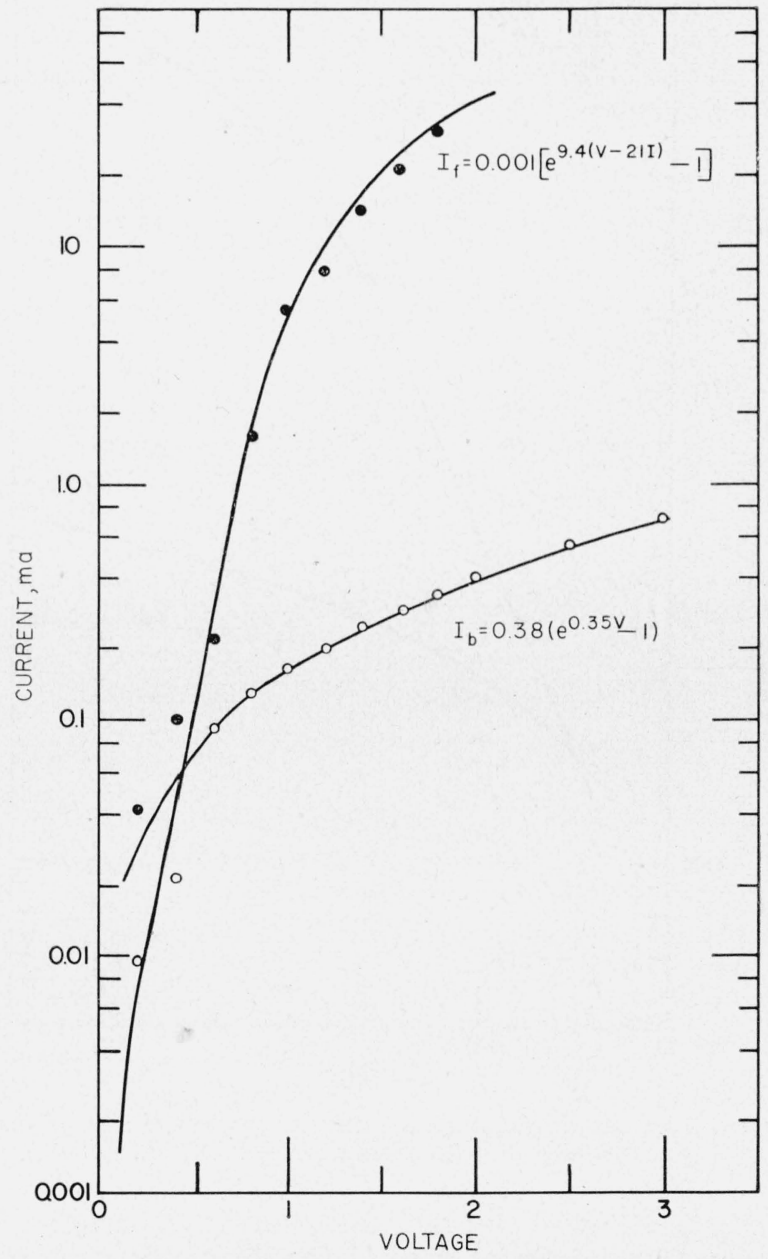

FIGURE 2. Analysis of direct-current characteristics of point contact titanium dioxide rectifier. 


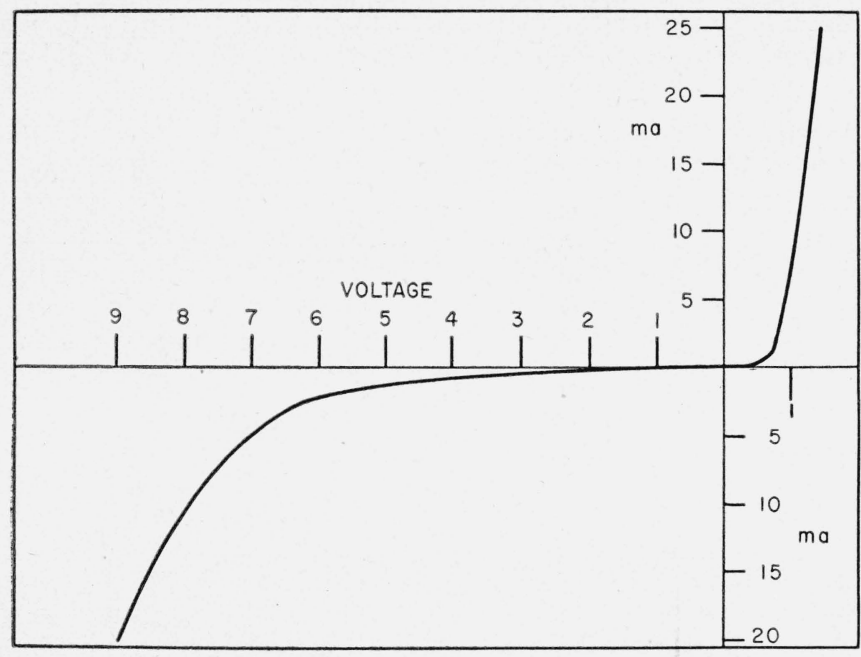

Figure 3. Direct-current characteristics from large area silver counter electrode on titanium dioxide rectifier made by two-step process.

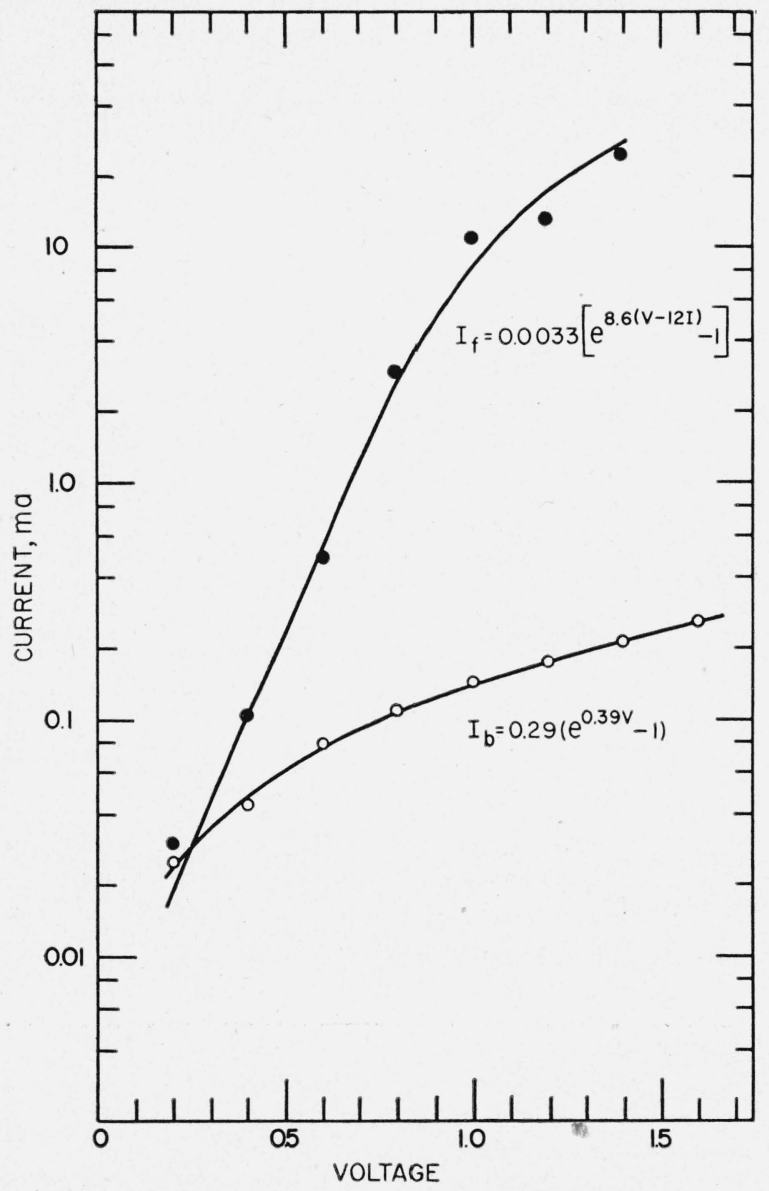

FIGURE 4. Analysis of direct-current characteristics of large contact area titanium dioxide rectifier.

$800^{\circ} \mathrm{C}$, followed by a reduction in hydrogen for about 15 minutes at $500^{\circ} \mathrm{C}$ for the production of a satisfactory rectifier.
However, some undesirable features of the units formed in this way were apparent. The results in general were rather erratic, indicating that in spite of the efforts made to control the conditions of reduction, the precautions were still insufficient. Similarly, a considerable lack of uniformity of the surface on a single sample was frequently noted. Finally, hydrogen is known to be rather soluble in titanium metal [15] and a great embrittlement of the metal results. This made the physical characteristics of the rectifiers rather undesirable for the fabrication of a practical device.

\section{Steam Treated Rectifiers}

The difficulties encountered in the control of the two-step process, coupled with the highly undesirable embrittlement of the titanium metal by both hydrogen and oxygen, led to a search for other possible reactions to produce the oxide layer. A thermodynamic calculation showed that a reaction of $\mathrm{Ti}$ metal with water vapor was possible and that either $\mathrm{TiO}_{2}$ or $\mathrm{Ti}_{2} \mathrm{O}_{3}$ were possible products. A series of exploratory studies was made to investigate the feasibility of this procedure. The results are presented in table 2. Coats described as very thin were less than 0.0001 in., very thick, greater than 0.005 in.

From the results of these explorations it was evident that the rather low temperature reactions were producing in one step an oxide layer whose physical properties were satisfactory and which was already a semiconductor with a conductivity in the desired range. Similarly, tests for rectification showed that quite satisfactory rectifiers were obtained from these units. A second series of samples was made at $600^{\circ}$ and $650^{\circ} \mathrm{C}$ for times ranging from 10 to 240 minutes. These samples were weighed before and after treatment to study the oxygen gain. While considerable scattering was found in the results for these rather short times, just as in the oxidation treatment, it seems that the results correspond roughly to a linear increase in $\Delta W / W$ with time up to about $3 \frac{11}{2}$ hours, the constants being $7 \times 10^{-3} / \mathrm{hr}$ for $600^{\circ} \mathrm{C}$ and $1 \times 10^{-2} / \mathrm{hr}$ for $650^{\circ} \mathrm{C}$. The film thickness was also found to increase more or less linearly with time up to about $12 \mu$, beyond which no reliable measurements could be made, probably because of flaking and chipping off of the oxide.

Studies were made of the rectification in these samples, using a silver-plated counter electrode and with an $0.08-\mathrm{cm}^{2}$ copper backing plate. Considerable rectification was found in all cases, although the reverse resistance was low in the short-time samples. Because it was apparent that the ability to withstand voltage in the reverse direction was the dominant factor, the breakdown voltage in the reverse direction was investigated, using the 0.08 $\mathrm{cm}^{2}$ electrode area.

The breakdown voltages measured were quite erratic but show a rough dependence on the square root of the forming time up to a maximum of about 25 volts at $600^{\circ} \mathrm{C}$ and 16 volts at $650^{\circ} \mathrm{C}$. The 
Table 2. Properties of titanium oxide film on steamed samples

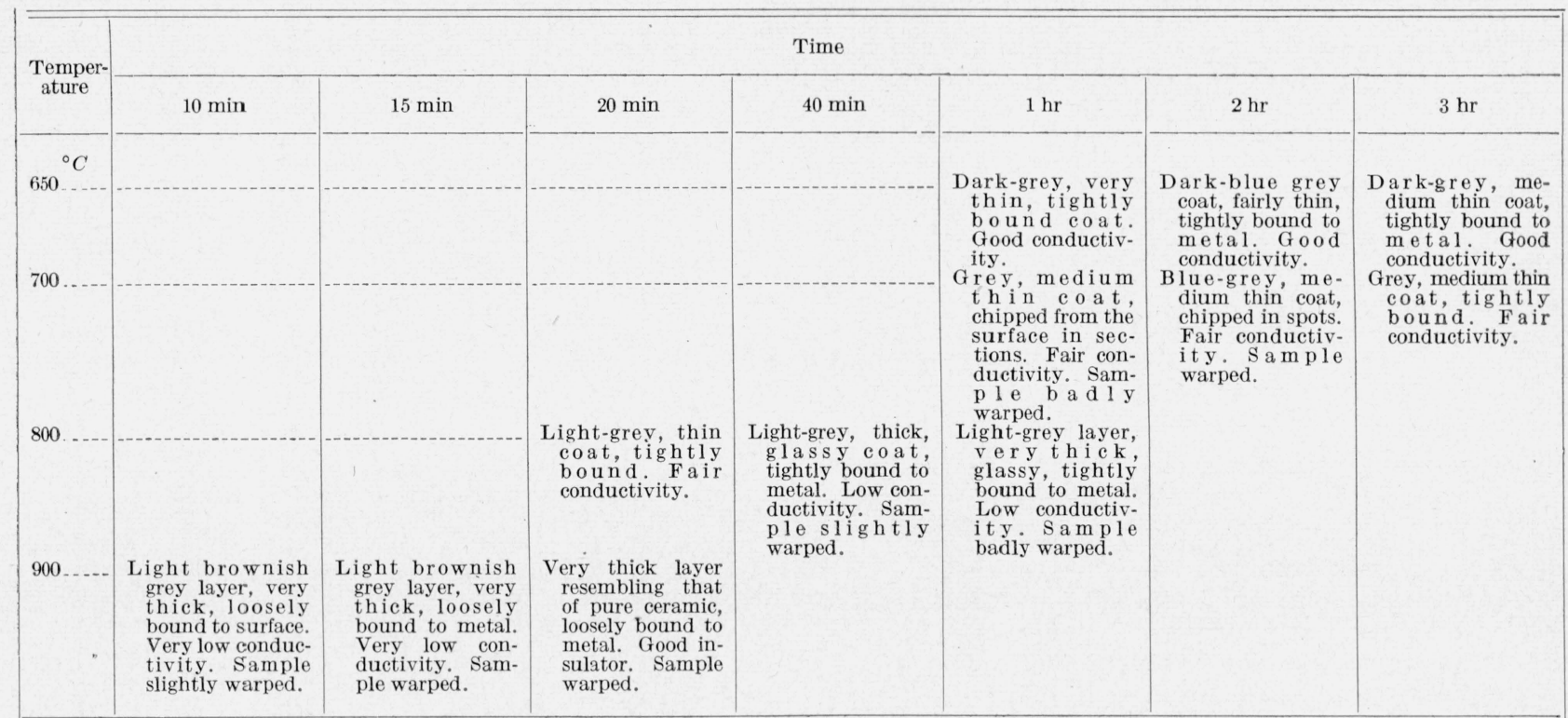

constant $A$ in an expression $V=A \sqrt{t}$ has the value of 1.2 volts $/ \mathrm{min}^{1 / 2}$ for the $600^{\circ} \mathrm{C}$ run and 1.1 volts/ $\min ^{3 / 2}$ for the $650^{\circ} \mathrm{C}$ series, with $V$ in volts and $t$ in minutes.

These measurements indicate that a forming treatment of about 3 hours in steam at 1 atmosphere and a temperature of $600^{\circ} \mathrm{C}$ produces a satisfactory rectifier.

The d-c properties of such a unit are shown in figures 5 and 6 . The solid lines in figure 6 are drawn for the equations $I_{f}=0.018\left(e^{4.08 \mathrm{v}}-1\right)$ and $I_{b}=0.12$ $\left(e^{0.47} \mathrm{v}-1\right)$ for $I$ in milliamperes and $V$ in volts. An analysis of the results, as done for figure 2, shows a spreading resistance of $10 \Omega$, indicating that the oxide layer produced in this way is almost identical with that formed in the two-step process.

A feature of great practical importance is the behavior of the rectifiers at elevated temperatures. The d-c characteristics at various temperatures were studied on a sample steam-treated for 3 hours at $600^{\circ} \mathrm{C}$ with silver counter electrodes. The results

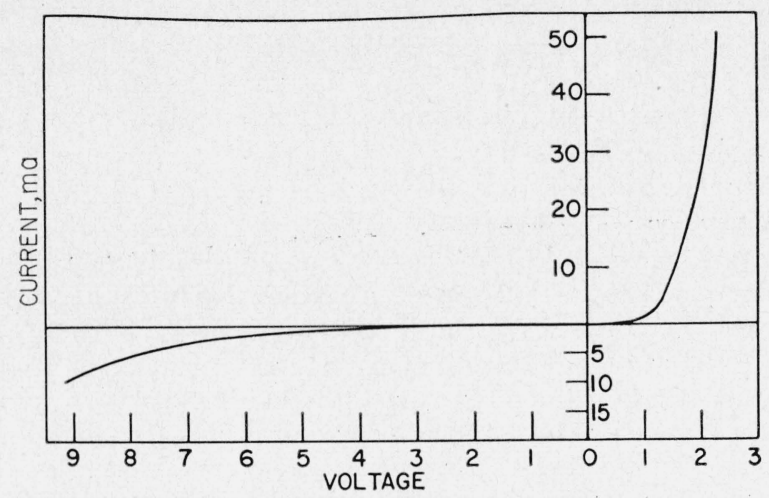

Figure 5. Direct-current rectifier characteristics from large area silver counter electrode on titanium dioxide rectifier made by one-step process.

Steam treated $3 \mathrm{hr}, 20 \mathrm{~min}$ at $600^{\circ} \mathrm{C}, 0.08 \mathrm{~cm}^{2}$ contact area, $\mathrm{Ag}$ plated electrode. are shown in figure 7 . It will be observed that the performance is actually improved by operation at temperatures up to about $140^{\circ} \mathrm{C}$, since the forward current is increased while the reverse current is somewhat reduced. Rectification is still observed at $200^{\circ} \mathrm{C}$, but the unit is damaged irreversibly by this treatment, the forward current being considerably reduced. An analysis of the data of figure 7 shows

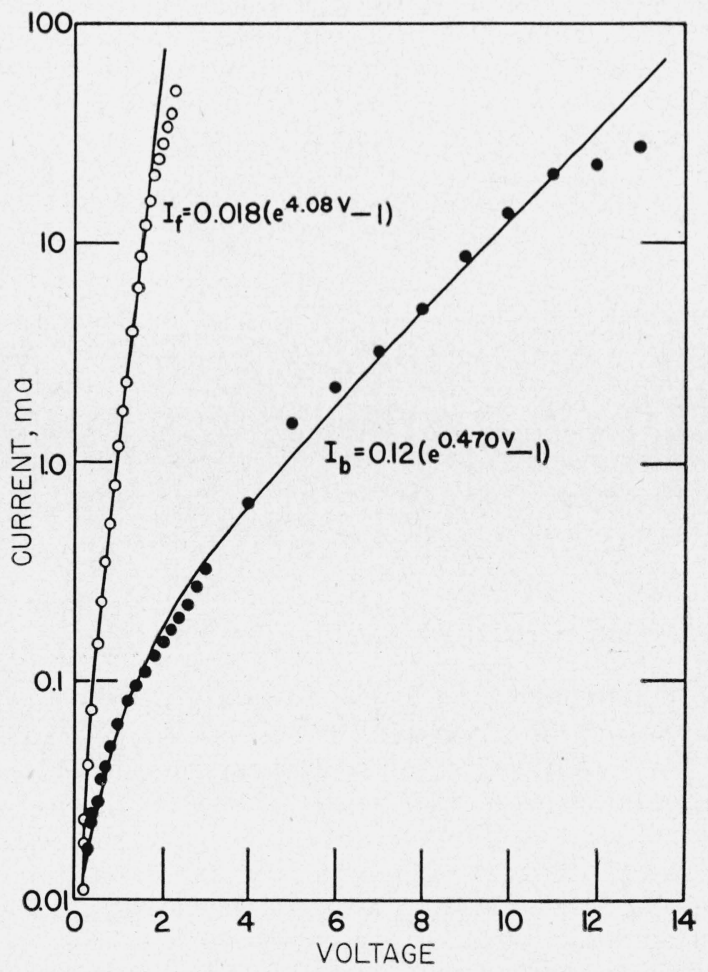

FIgure 6. Analysis of direct-current characteristics of large contact area titanium dioxide rectifier from one-step prosess.

Steam treated $3 \mathrm{hr}, 20 \mathrm{~min}$ at $600^{\circ} \mathrm{C}, 0.08 \mathrm{~cm}^{2}$ contact area, Ag plated electrode 


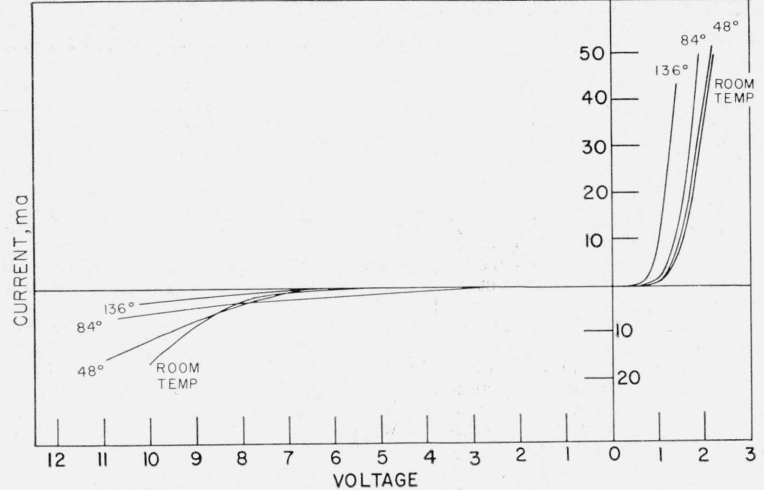

FiguRE 7. Direct-current titanium dioxide rectifier characteristics at elevated temperature.

Steam treated at $600^{\circ} \mathrm{C}$ for $3 \mathrm{hr}, 20 \mathrm{~min}, 0.08-\mathrm{cm}^{2}$ contact area, Ag plated electrode.

that $A, r$, and $\alpha$ in eq 1 and 2 are a function of temperature for both forward and reverse currents. The values for these constants (for voltages $\geq 0.5 \mathrm{v}$ ) at the various temperatures are given in table 3 . The effect of the thermal treatment on the barrier is clearly illustrated by the behavior of $r$. For temperatures up to $136^{\circ} \mathrm{C}, r$ in general is reduced presumably by the increase in number of charge carriers in the semiconducting layer. There is a sudden increase in $r$ by an order of magnitude near $160^{\circ} \mathrm{C}$ and a further increase at $200^{\circ} \mathrm{C}$ probably brought about by a partial reoxidation of the semiconductor layer.

Detailed life studies have not yet been performed on the rectifiers, but one unit was maintained at $85^{\circ} \mathrm{C}$ with 10 volts applied in the reverse direction for a period of 28 days with an increase in current only from 1.65 to $3.1 \mathrm{ma}$.

TABLE 3. Direct-current characteristics of samples measured at various temperatures

$$
I_{f}=A_{f}\left(e^{\alpha_{f}\left(V-I_{f} r\right)}-1\right) ; I_{b}=A_{b}\left(e^{\alpha_{b} V}-1\right)
$$

\begin{tabular}{|c|c|c|c|c|c|}
\hline Temperature & $\alpha_{f}$ & $A_{f}$ & $r$ & $\alpha_{b}$ & $A_{b}$ \\
\hline $\begin{array}{r}{ }^{\circ} \mathrm{C} \\
25 \\
48 \\
84 \\
136 \\
160 \\
200\end{array}$ & $\begin{array}{c}v^{-1} \\
6.42 \\
7.71 \\
8.82 \\
12.0 \\
7.12 \\
9.05\end{array}$ & $\begin{array}{c}m a \\
0.001 \\
.0003 \\
.00037 \\
.00012 \\
.0031 \\
.0016\end{array}$ & $\begin{array}{r}\text { Ohms } \\
11.8 \\
13.3 \\
11.7 \\
9.0 \\
95.0 \\
115.0\end{array}$ & $\begin{array}{c}v^{-1} \\
0.793 \\
.286 \\
.90 \\
.144 \\
.300 \\
.254\end{array}$ & $\begin{array}{c}m a \\
0.009 \\
.019 \\
.03 \\
.69 \\
1.22 \\
.707\end{array}$ \\
\hline
\end{tabular}

\section{Counter Electrode Effects}

While the current theories of rectification [4 and 5] suggest that the constant $A_{f}$ in eq 1 is related to $e^{(e / k T) \phi_{0}}$, where $\phi_{0}$ is the work function of the contact metal, this is not clearly observed in practice, although $A_{f}$ does depend on the nature of the counter electrode. Such a dependance has also been observed in the titanium dioxide rectifiers. A series of measurements has been made on a duplicate set of samples treated in steam for 3 hours at $600^{\circ} \mathrm{C}$. The counter electrodes were electrodeposited for 30 seconds using a-c deposition, and the samples were

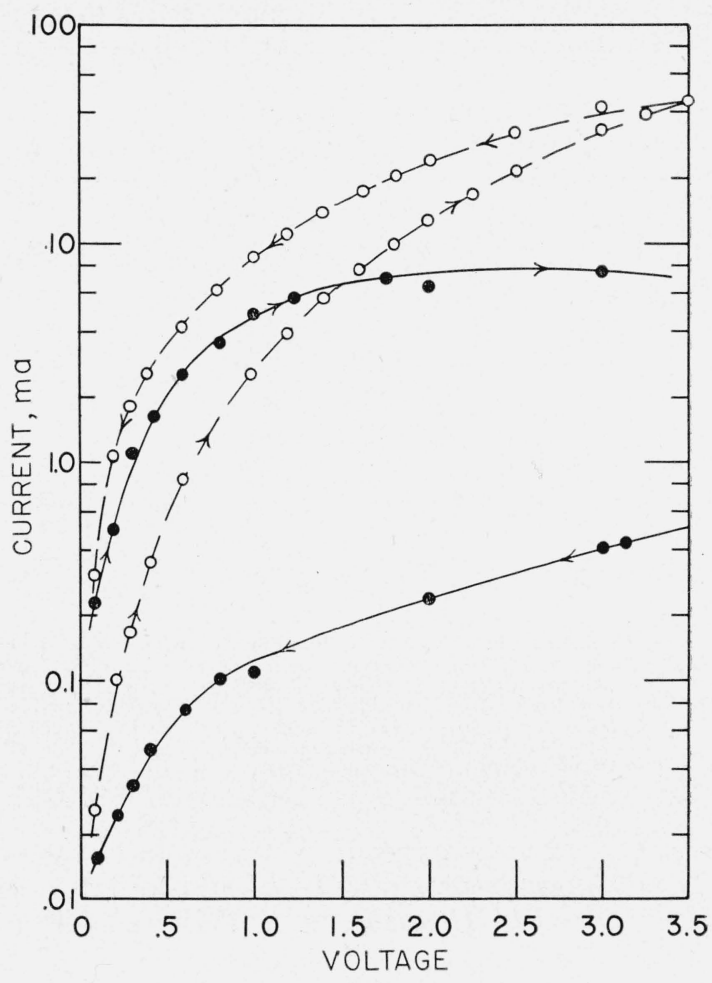

Figure 8. Direct-current titanium dioxide rectifier characteristics for zinc counter electrode.

Forward $\bigcirc$; reverse

then measured with $0.08-\mathrm{cm}^{2}$ copper contact plate. The counter electrode metals were $\mathrm{Ag}, \mathrm{Au}, \mathrm{Sb}, \mathrm{Cu}$, $\mathrm{Ni}, \mathrm{Zn}$, and $\mathrm{Cd}$. Rectification is observed in all cases, but some rather striking differences are noted in the characteristics. The metals fall naturally into three groups: those metals low on the electromotive series and hence not readily oxidizable, for example, $\mathrm{Ag}, \mathrm{Au}$, and $\mathrm{Sb}$; those forming $n$-type semiconducting oxides fairly readily, for example, $\mathrm{Zn}$ and $\mathrm{Cd}$; and those metals forming $p$-type semiconducting oxides fairly readily, for example, $\mathrm{Cu}$ and $\mathrm{Ni}$. The observed rectifier characteristics also fall into three groups. The inert metals give rectifiers with reasonably similar properties, although the $\mathrm{Sb}$ gives a somewhat smaller reverse current than the $\mathrm{Au}$ or $\mathrm{Ag}$. Some hysteresis effects were noticed with these electrodes, but they are not conspicuous.

For a zinc counter electrode a striking change in properties was observed. The d-c forward current shown in figure 8 increases rather slowly with increasing voltage, although reaching normal values at about 3.0 volts. With decreasing voltages the forward current is noticeably greater than with increasing voltages, and for very low voltages is appreciably greater than that observed for the inert electrodes. The behavior of the $\mathrm{d}$-c reverse current shown for low voltages in figure 8 and for higher voltages in figure 9 is even more striking. For voltages less than 1.5 , the reverse current is considerably larger than the forward current for the same 


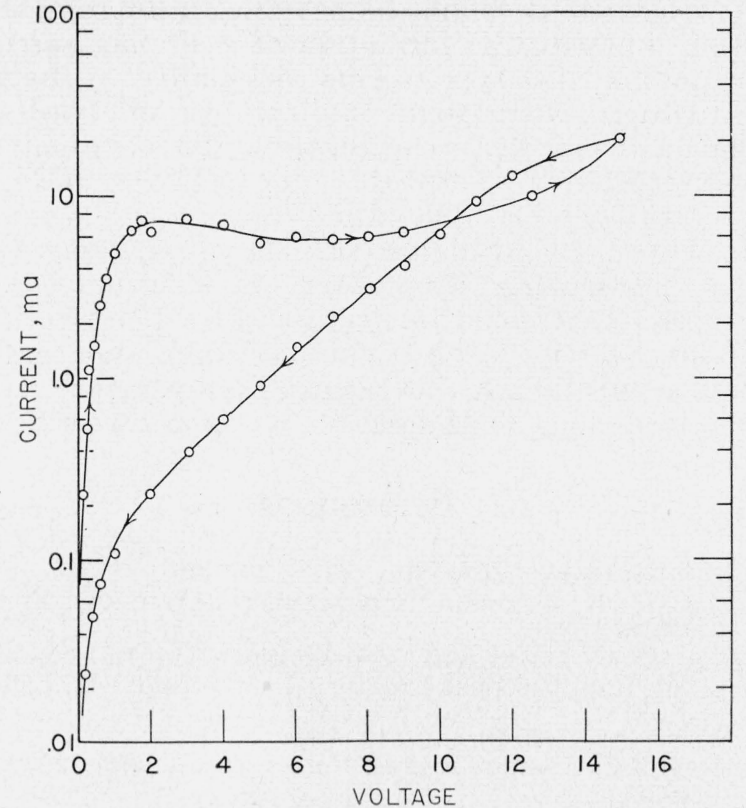

Figure 9. Direct-current titanium dioxide rectifier characteristics for zinc counter electrode for large reverse voltages.

voltage. The reverse current reaches a maximum near 2 volts and then remains relatively constant to about 10 volts, when it commences to increase slowly. As the voltage is lowered, the current at first is somewhat greater than with increasing voltages, but for voltages below about 10 , the current is very much less than observed for increasing voltage. If a $60 \mathrm{c} / \mathrm{s}$ a-c test is made, and the characteristics are displayed on an oscilloscope, as described in the reference in footnote 2 , the current-voltage characteristics show nonlinearity but very poor rectification. It is apparent that the blocking layer found in the $d-c$ measurements is a polarization effect and, from some observations of the time of formation of the layer, which is of the order of seconds, can only be due to an ionic process.

With a $\mathrm{Cd}$ counter electrode an unusually large forward current was observed, the constants being $A_{f}=0.049 \mathrm{ma}$ and $\alpha_{f}=15.3$ volts $^{-1}$; a somewhat larger than normal reverse current $A_{b}=6.3$ ma and $\alpha_{b}=0.19$ volts $^{-1}$, but the hysteresis effects were small.

For the metals forming $p$-type oxides a somewhat different situation was observed. With copper a better than normal forward current was found, particularly at low voltages, and a small reverse current was also obtained. The effects were even more striking with a nickel counter electrode. Again, an increased forward current at low voltages was found and the reverse current was notably small. These d-c measurements show rather pronounced hysteresis effects, particularly in the reverse direction. When the rectification was observed on $60 \mathrm{c} / \mathrm{s}$ a-c test, the forward current behaves in a normal manner, but the reverse current is small only for low voltages and increases suddenly at about 4 volts reverse. This again indicates that the $\mathrm{d}$-c properties are influenced by a slow polarization process.
TABLE 4. Direct-current rectifier characteristics for various counter electrodes

\begin{tabular}{|c|c|c|c|c|c|c|}
\hline Metal & $\phi_{0}$ & $A_{f}$ & $\alpha_{\mathrm{f}}$ & $A_{b}$ & $\alpha_{b}$ & \\
\hline & $e v$ & $m a$ & $v^{-1}$ & $m a$ & $v^{-1}$ & \\
\hline $\mathrm{Au}$ & 4. 78 & 0.20 & 3.8 & 20 & 0.05 & \\
\hline $\mathrm{Ag}$ & 4. 6 & .38 & 2.7 & 5. 9 & .10 & \\
\hline $\mathrm{Sb}$ & 4. 6 & .40 & 3.2 & 0.04 & .40 & \\
\hline $\mathrm{Ni}$ & 5.0 & .042 & 5.1 & .032 & 49 & $\begin{array}{l}\text { Increasing } \\
\text { voltage. }\end{array}$ \\
\hline $\mathrm{Ni}$ & 5.0 & .0059 & 13.8 & .035 & .84 & Decreasing \\
\hline $\mathrm{Cu}$ & 4.1 & .31 & 3.9 & .22 & .50 & Increasing \\
\hline $\mathrm{Cu}$ & -..... & -. & & .31 & .28 & Decreasing \\
\hline $\mathrm{Cd}$ & 4.1 & .049 & 15. 3 & 6.3 & .19 & voltage. \\
\hline $\mathrm{Zn}$ & 3.3 & 2.0 & 1.3 & - & - & Increasing \\
\hline $\mathrm{Ti}$ & 4. 18 & ...... & -.... & - & - & - not. \\
\hline
\end{tabular}

It should be mentioned that no permanent "electroforming" effects have thus far been noted, although they would be anticipated in view of these counter electrode effects. The data for these d-c characteristics are summarized in table 4. The photoelectric work functions of the various metals are included [18]. The value for Ti is that given by Rentschler and Henry [19.]

It is apparent that the constant $A$ is not directly related to $\exp \left(e \phi_{0} / k T\right)$, but that the counter electrode influences the properties of the unit in some other fashion. It should be stressed that too great reliance should not be placed on the individual values of $A$ and $\alpha$ in table 4 because a considerable variation between samples has been noticed. Compare, for example, the data for a silver counter electrode in tables 3 and 4 and figure 4 . The general properties mentioned have, however, been observed in all specimens tested.

\section{Discussion}

It seems evident that the rectifier described here has considerable possibilities, even though it has not yet been investigated in great detail. The ease of preparation of the units, particularly by the steam process, and the quality of their performance at such an early stage in their development are very encouraging, although a great deal of study will be needed to assess their practicality. Similarly, a much more intensive study of many of the properties will be needed to obtain a clear picture of the nature of the rectification process. The information obtained thus far does, however, give some grounds for preliminary speculation.

The nature and location of the asymmetric potential barrier is of great interest in any interpretation of the rectification mechanism. In all rectifier types thus far discovered the direction of easy flow of charge carriers over the barrier is from the semiconductor to the metal electrode. Because $\mathrm{TiO}_{2}$ is an $n$-type semiconductor, the charge carriers are electrons; and since we have observed the forward direction to be that with the counter electrode positive, we must conclude that the barrier layer is located between the counter electrode and the semiconductor. This is suggested also by the observation of the counter electrode effects; if 
the barrier were located between the oxide and the titanium base, the counter electrode would not be expected to have much influence on the rectifier characteristics.

It is possible that the barrier is a "physical" barrier of the Schottky type, but extensive measurements, particularly of the a-c characteristics, will be required to establish agreement with the predictions of the Schottky theory $[2,5,6]$. Such measurements are in progress. A "chemical" barrier of the Mott type [4] seems less likely to be present. Although it might be assumed that a film of nearly stoichiometric $\mathrm{TiO}_{2}$ exists on the free surface during the steam treatment, the opposite situation would be normally expected in the reduction of the oxide film by hydrogen, and the free surface presumably would be the most strongly reduced. Another mechanism of rectification considered by Fan [20] may be possible in this situation. Fan showed that rectification was possible if a semiconducting film separates two metals with different work functions. This is supported by the striking behavior noted with the $\mathrm{Zn}$ counter electrode, since $\mathrm{Zn}$ was the only metal investigated whose work function is clearly lower than that reported for $\mathrm{Ti}$. On the other hand, no direct dependence on the value of the work function for metals with $\phi_{0} \geq 4.2$ is indicated in the values of the constants in table 4 .

Possibly even more suggestive is the fact that unusual properties were noted with counter electrodes that might be rather reactive chemically. The observed excellent d-c characteristics for the metals forming $p$-type oxides might imply that the formation of a $p-n$ junction layer was aiding the rectification; conversely, a $\mathrm{Zn}$ counter electrode which forms an $n$-type oxide impaired the rectification. These effects, of course, would not explain the good rectification observed with supposedly inert counter electrodes unless it was postulated that compound formation took place in the surface layer in all cases. Even this assumption would, however, not explain the "normal" behavior of the Cd counter electrode which is known to form an $n$-type oxide [21]. It seems likely, in fact, that several mechanisms for rectification are operating in the combination, and evidently a great deal of study will be needed to assess the relative importance of the various processes.

It would seem, in view of these counter electrode effects in which a transient barrier is formed in each half-cycle, that it should be possible to improve the existing units by the formation of a similar barrier of a permanent type. This possibility is being investigated, with some indications of success.

The particular feature of these rectifiers of greatest practical interest is probably the behavior at high temperatures. The difficulties encountered in most units currently available [22] have stressed the utility, particularly for military applications, of a power unit that could be operated at a temperature of about $150^{\circ} \mathrm{C}$. The titania rectifiers apparently are quite effective in this range of temperature, and so merit serious consideration as power rectifiers.

\section{References}

[1] L. O. Grondahl, Phys. Rev. 27, 813 (1926).

[2] e. g., H. K. Henisch, Metal rectifiers (Clarendon Press, Oxford, 1949).

[3] e. g., H. C. Torrey and C. A. Whitmer, Crystal rectifiers (McGraw-Hill Book Co., Inc., New York, N. Y., 1948).

[4] N. F. Mott, Proc. Roy. Soc. [A] 171, 27 (1939).

[5] W. Schottky, Z. Physik 113, 367 (1939).

[6] W. Schottky and F. Waibel, Naturwissenschaften 20, 297 (1932).

[7] J. W. Hickman and E. A. Gulbransen, J. Anal. Chem. 20, 158 (1948).

[8] W. Meyer, Physik. Z. 36, 749 (1935)

[9] W. Meyer and H. Neldel, Physik. Z. 38, 1014 (1937).

[10] M. Earle, Phys. Rev. 61, 56 (1942).

[11] A. von Hippel, R. G. Breckenridge, A. P. de Bretteville, Jr., and J. M. Brownlow, N. D. R. C. Rept. 540, Lab. for Insulation Research M. I. T., Oct. 1945.

[12] R. G. Breckenridge and W. R. Hosler, unpublished data.

[13] Tech. Information on Ti Metal, Remington Arms Co., Bridgeport, Conn. (1949).

[14] W. A. Alexander and L. M. Pigeon, Canadian J. Research B28, 60 (1950).

[15] E. A. Gulbransen and K. F. Andrews, Trans. A. I. M. E. 185, 741 (1949).

[16] M. H. Davies and C. E. Birchenall, Trans. A. I. M. E., J. Metals, 877 (1951).

[17] N. Nasu, Sci. Repts. Tồhoku Imp. Univ. 25, 510 (1936).

[18] A. L. Hughes and L. A. duBridge, Photoelectric phenomena, McGraw-Hill Book Co., Inc., New York, N. Y., (1932).

[19] H. C. Rentschler and D. E. Henry, Trans. Electrochem. Soc. 87, 289 (1945).

[20] H. Y. Fan, Phys. Rev. 74, 1505 (1948).

[21] H. H. v. Baumbach and W. Wagner, Z. Physik, Chem. B22, 208 (1933)

[22] W. F. Bonner and F. J. Oliver, Elect. Mfg. 48, No. 4, 128 (1951).

Washington, May 26, 1952. 